\title{
PEREKAT UNTUK PEMBUATAN PELET PUPUK ORGANIK DARI RESIDU PROSES DIGESTASI ANAEROBIK LUMPUR BIOLOGI INDUSTRI KERTAS
}

\author{
Krisna Adhitya Wardhana ${ }^{1}$, Rina S. Soetopo, Saepulloh, Prima Besty Asthary, Mukharomah Nur Aini \\ Balai Besar Pulp dan Kertas, Jl. Raya Dayeuhkolot No 132 Bandung \\ ${ }^{1}$ krisnaadhitya@gmail.com
}

Diterima : 4 Mei 2015, Revisi akhir : 12 Oktober 2015, Disetujui terbit : 23 November 2015

\begin{abstract}
THE ADHESIVES FOR ORGANIC FERTILIZER PELLETIZATION FROM THE ANAEROBIC DIGESTION RESIDUE OF PAPER MILL BIOLOGICAL SLUDGE
\end{abstract}

\begin{abstract}
The residue from anaerobic digestion of paper mill biological sludge has the potency to be used as organic fertilizer. Physically, organic fertilizer in pellet form has smaller volume and easily stored and transported. The aim of this study is to obtain the appropriate adhesive to make fertilizer pellets from the residue from anaerobic digestion of paper mill biological sludge. The experiment were performed with two variable treatments which are the types of adhesive (sago flour, cassava starch, molasses) and the adhesive doses $(0.5 \%, 1.0 \%$, and $1.5 \%)$ with respectively 3 replications. The physical properties of resulting pellets were tested including yield, density, water holding capacity, and durability. The effect of pellets on plant germination and growth was also done using tomato seed. The results explained that generally, the pellets meet minimum requirements of organic fertilizers and soil conditioner according to Indonesian National Standard (SNI 7847:2012) unless Zn as micro nutrient and Regulation of the Minister of Agriculture Number 70/2011 unless water content. The pelletization of organic fertilizer to the size of 3-5 $\mathrm{mm}$ can be done by adding the best adhesive material, namely cassava starch 1\% with the physical properties of the pellets including a yield of $99.56 \%$, density of $1.84 \mathrm{~g} / \mathrm{mL}$, water holding capacity of $65.53 \%$, and durability of $99.65-99.84 \%$, but organic fertilizer pellets (with sago flour as adhesive) at a dose of $0.5 \mathrm{~g} / 50 \mathrm{~g}$ media is the best for tomato germination and growth.
\end{abstract}

Keywords: anaerobic digestion residue, organic fertilizer pellet, molasses, cassava starch, sago flour

\begin{abstract}
ABSTRAK
Residu proses digestasi anaerobik lumpur biologi industri kertas berpotensi dimanfaatkan sebagai pupuk organik. Secara fisik, pupuk organik dalam bentuk pelet lebih kecil volumenya dan lebih mudah disimpan dan diangkut. Tujuan penelitian ini adalah untuk memperoleh bahan perekat yang sesuai untuk membuat pelet pupuk organik dari residu proses digestasi anaerobik lumpur biologi industri kertas. Percobaan dilakukan dengan 2 variabel perlakuan, yaitu jenis perekat (tepung sagu, tepung kanji, molase) dan dosis perekat $(0,5 \% ; 1,0 \%$; dan $1,5 \%)$ dengan masing-masing 3 replikasi. Pelet yang dihasilkan diuji sifat fisiknya meliputi yield, densitas, water holding capacity dan durabilitas. Percobaan pengaruh pelet berperekat terhadap perkecambahan dan pertumbuhan biji tanaman tomat juga dilakukan. Hasil penelitian menjelaskan bahwa secara umum, pelet memenuhi persyaratan minimal pupuk organik dan pembenah tanah sesuai SNI 7847:2012 kecuali Zn sebagai unsur hara mikro dan PERMENTAN No. 70 tahun 2011 kecuali kadar air. Pembuatan pelet pupuk organik dengan ukuran 3-5 mm dapat dilakukan dengan menambahkan bahan perekat terbaik, yaitu tepung kanji $1 \%$ dengan sifat fisik : yield $99,56 \%$, densitas $1,84 \mathrm{~g} / \mathrm{mL}$, water holding capacity $65,53 \%$ dan durabilitas $99,65-99,84 \%$, namun penggunaan pelet pupuk organik (berperekat tepung sagu) $0,5 \mathrm{~g} / 50 \mathrm{~g}$ media untuk perkecambahan dan pertumbuhan biji tanaman tomat merupakan yang terbaik.
\end{abstract}

Kata kunci: residu digestasi anaerobik, pelet pupuk organik, molase, tepung kanji, tepung sagu 


\section{PENDAHULUAN}

Lumpur biologi dari Instalasi Pengolahan Air Limbah (IPAL) industri kertas bersifat voluminous dan sulit dihilangkan airnya, sehingga masih menjadi masalah dalam pengelolaannya. Pengelolaan yang umum dilakukan di industri kertas hingga saat ini adalah dipress pada mesin belt press, namun kurang efektif. Oleh karena itu, perlu dicari alternatif pengelolaan yang lebih baik.

Digestasi anaerobik merupakan salah satu alternatif proses penanganan lumpur biologi IPAL melalui penguraian bahan organik oleh bakteri anaerobik. Hasil dari proses ini, selain menghasilkan biogas, menghasilkan endapan atau residu berupa lumpur. Lumpur tersebut mengandung unsur-unsur hara esensial yang berpotensi untuk dimanfaatkan sebagai pupuk organik (Rina dkk., 2012).

Secara fisik, pupuk organik dapat dibedakan dalam bentuk curah dan pelet. Pupuk organik dalam bentuk curah memiliki beberapa kekurangan, antara lain lebih cepat kering dan mudah tersapu oleh hembusan angin sehingga sulit untuk diaplikasikan (Suriadikarta dan Setyorini, 2006). Selain itu, pupuk curah juga dapat menimbulkan debu dan kondisi overdosis pada tanaman karena pelepasan nutrisi secara mendadak (Utari dkk., 2015).

Salah satu cara untuk mengatasi kekurangan pupuk curah tersebut adalah dengan membuat pupuk organik dalam bentuk pelet. Wahyono dkk. (2011) menyatakan pupuk dalam bentuk pelet dapat mengurangi overdosis tanaman, memperbaiki penampilan dan kemasan produk. Hara (2001) menambahkan bahwa pupuk dalam bentuk pelet memiliki kelebihan, yaitu dapat mereduksi volume sampai $50-80 \%$ dan juga mereduksi debu sehingga lebih mudah diangkut untuk jarak jauh. Namun, pupuk organik dalam bentuk pelet memiliki beberapa kelemahan yang antara lain mudah pecah dan hancur. Kelemahan ini dapat diatasi dengan menambahkan bahan perekat dalam pembuatan pelet. Perekat merupakan salah satu faktor penting dalam proses pembuatan pelet. Fungsi dari perekat dalam pembuatan pelet adalah untuk meningkatkan sifat fisik pelet terutama kekompakan pelet. Pemilihan dan penggunaan jumlah perekat dalam pembuatan pelet perlu diperhatikan. Jika terlalu sedikit, pelet yang dihasilkan tidak sempurna atau mudah pecah. Sebaliknya, jika terlalu banyak digunakan, maka pori-pori bahan pelet akan tertutup.
Perekat yang digunakan harus memiliki sifat rekat yang baik, tidak membahayakan terhadap tanaman dan juga harganya terjangkau (Isroi, 2009). Utari dkk. (2015) menggunakan tanah liat dan tapioka sebagai perekat dalam pembuatan pupuk granul. Nikiema dkk. (2013) melakukan penelitian pembuatan pelet pupuk organik dari lumpur domestik dengan bahan perekat pregelatinized starch dengan konsentrasi optimum 3\%.

Atas dasar uraian tersebut, penelitian ini dilakukan dengan tujuan karakterisasi residu lumpur proses digestasi anaerobik sebagai pupuk organik curah dan menentukan jenis bahan perekat yang sesuai untuk mengubah bentuk fisik pupuk organik tersebut dari bentuk curah menjadi bentuk pelet. Makalah ini membahas pengaruh penambahan perekat terhadap kualitas fisik pelet pupuk organik dari lumpur hasil proses digestasi anaerobik. Penambahan perekat tersebut diharapkan dapat meningkatkan kualitas fisik pelet pupuk. Selain itu, juga membahas pengaruh penggunaan pelet pupuk organik terhadap perkecambahan dan pertumbuhan bibit tanaman tomat (Lycopersicum esculentum).

\section{BAHAN DAN METODE}

\section{Bahan}

Beberapa bahan yang digunakan pada penelitian ini antara lain residu proses digestasi anaerobik lumpur biologi IPAL industri kertas, tiga jenis perekat untuk pembuatan pelet (tepung kanji, tepung sagu, molase), bibit tomat varietas Permata F1 yang diperoleh dari PT East West Seed Indonesia, pasir dengan kandungan organik maksimal 1,5\%, dan air reverse osmosis (RO).

\section{Metode}

\section{Karakterisasi Residu Digestasi Anaerobik}

Residu proses digestasi anaerobik lumpur biologi IPAL industri kertas berupa endapan lumpur yang telah dikeringkan (dewatering) hingga kadar air sekitar 75\%. Karakterisasi residu lumpur tersebut meliputi beberapa parameter yaitu C-organik, N-organik, bahan ikutan, $\mathrm{pH}$, kadar air, unsur hara makro dan hara mikro. Pengujian parameter-parameter tersebut dilakukan di laboratorium uji Balai Penelitian Tanah-Bogor. Evaluasi data dilakukan dengan 
cara membandingkan dengan standar baku mutu pupuk organik atau kompos menurut SNI 7847:2012 "Limbah-Spesifikasi hasil pengolahanBagian 1: Lumpur (Sludge) IPAL Industri Pulp dan Kertas Untuk Pembenah Tanah Organik" dan PERMENTAN No. 70 tahun 2011 tentang "Pupuk Organik, Pupuk Hayati, dan Pembenah Tanah : Tabel Persyaratan Teknis Minimal Pupuk Organik dari IPAL Industri, Tabel Persyaratan Teknis Minimal Pupuk Organik Padat Granul/ Pelet Murni, Tabel Persyaratan Teknis Minimal Pupuk Organik Padat Remah/Curah Murni”.

\section{Pembuatan Pelet Pupuk Organik}

Residu lumpur yang telah memenuhi syarat sebagai pupuk organik diubah bentuk fisiknya dari bentuk curah menjadi bentuk pelet. Tahapan pembuatan pelet pupuk organic adalah residu lumpur dikeringkan (dewatering) hingga kadar air sekitar $75 \%$, kemudian dicampur dengan perekat sesuai dengan variasi dosis yang telah ditetapkan sampai homogen. Campuran yang telah homogen tersebut dicetak dengan alat pencetak pelet berlubang dengan diameter $5 \mathrm{~mm}$ dan dikeringkan hingga kadar air sekitar 9\%.

Percobaan pembuatan pelet dilakukan dengan 2 variabel perlakuan dengan masing-masing 3 taraf dan 3 replikasi. Masing-masing variabel perlakuan tersebut sebagai berikut:

a. jenis perekat: tepung kanji, tepung sagu, dan molase

b. dosis perekat: $0,5 \% ; 1 \% ; 1,5 \%$

Pengamatan dilakukan terhadap beberapa parameter sifat fisik yang terdiri dari uji yield, uji densitas, uji daya pegang air (water holding capacity), dan uji ketahanan gesek (durabilitas).

\section{Pengujian Sifat Fisik Pelet Pupuk Organik}

Pengujian sifat fisik dilakukan terhadap pelet pupuk organik yang telah kering dengan parameter uji meliputi yield, densitas (Allaire dan Parent, 2003), water holding capacity (Beyl, 2015) dan durabilitas (Alemi dkk., 2010).

Uji yield dilakukan untuk mengetahui jumlah pelet yang memiliki ukuran $2-5 \mathrm{~mm}$ sesuai dengan persyaratan PERMENTAN No. 70 tahun 2011. Pengujian dilakukan menggunakan saringan dengan diameter lubang 3 dan $5 \mathrm{~mm}$. Penimbangan dilakukan terhadap pelet yang lolos saringan $5 \mathrm{~mm}$ dan tertahan pada saringan
$3 \mathrm{~mm}$. Rumus perhitungan yield pelet pupuk organik mengacu pada Utari dkk. (2015) dengan modifikasi ukuran saringan seperti pada Persamaan 1.

yield $(\%)=\frac{M_{2}}{M_{1}} \times 100 \%$

dengan:

$M_{2}$ : massa pelet lolos saringan $5 \mathrm{~mm}$ dan tertahan pada saringan $3 \mathrm{~mm}(\mathrm{~g})$

$M_{1}$ : massa pelet yang diuji (g)

Uji densitas dilakukan mengacu pada ASAE S269.4 DEC96: Cubes, Pellets, and CrumblesDefinitions and Methods for Determining Density, Durability, and Moisture Content. Prinsip uji densitas adalah penimbangan dan pengukuran volume pelet untuk mengetahui kepadatan dan kekompakan partikel penyusun pelet. Pada percobaan ini, uji densitas dilakukan dengan cara menimbang pelet sebanyak 5 gram dan dimasukkan ke dalam gelas ukur berisi $5 \mathrm{ml}$ akuades, dibiarkan hingga tidak ada gelembung udara pada pelet, kemudian diukur volume campuran air dan pelet tersebut. Nilai densitas dihitung dengan Persamaan 2.

Densitas $\left(\frac{g}{m l}\right)=\frac{M_{p}}{\left(V_{2}-V_{1}\right)}$

dengan :

$M_{p}$ : massa pelet pupuk (g)

$V_{1}^{p}$ : volume akuades sebelum penambahan pelet pupuk $(\mathrm{mL})$

$V_{2}$ : volume akuades setelah penambahan pelet pupuk $(\mathrm{mL})$

Prinsip pengujian water holding capacity mengacu pada Viji dan Rajesh (2011). Pengujian ini dilakukan untuk mengetahui kemampuan pelet pupuk dalam menyerap air. Perhitungan nilai water holding capacity dengan Persamaan 3.

WHC $(\%)=\frac{M_{p 1}-M_{p 2}}{M_{p 2}}$

dengan :

WHC : water holding capacity $(\%)$

$M_{p l} \quad$ : massa pelet pupuk basah (g)

$M_{p 2}^{p 1}$ : massa pelet pupuk kering $(\mathrm{g})$

Prinsip pengujian durabilitas mengacu pada ASAE S269.4 DEC96. Uji ini bertujuan untuk 
mengetahui ketahanan pelet pada kondisi adanya gesekan dan tekanan tertentu. Peralatan yang digunakan adalah shaker bath dan saringan berdiameter $3 \mathrm{~mm}$ dan $5 \mathrm{~mm}$. Lama penyaringan adalah 45 menit. Perhitungan nilai durabilitas pelet dengan Persamaan 4.

Durabilitas (\%) $=\frac{M_{b}}{M_{a}} \times 100 \%$

dengan:

$M_{a} \quad$ : massa pelet pupuk sebelum uji (g)

$M_{b}^{a} \quad$ : massa pelet pupuk sesudah uji (g)

\section{Pengaruh Pelet Pupuk Organik terhadap Perkecambahan Biji Tanaman Tomat}

Percobaan pengaruh pelet pupuk organik terhadap perkecambahan tanaman mengacu pada OECD Guidelines For Testing of Chemicals: Terrestrial Plant Test: 208: Seedling Emergence and Seedling Growth Test (www.oecd.org). Tanaman yang digunakan adalah biji tomat (Lycopersicum esculentum). Perlakuan percobaan menggunakan rancangan faktorial dengan 2 variabel dan 6 replikasi, yaitu :

a. Pelet pupuk dengan variasi jenis perekat meliputi tepung sagu, tepung kanji, dan molase.

b. Dosis pelet pupuk (g pelet/ 50 g media) antara lain 0,$125 ; 0,250 ; 0,375: 0,50$ yang masing-masing setara dengan $5 ; 10 ; 15 ; 20$ (ton/ha).

Percobaan dilengkapi kontrol negatif (tanpa pelet pupuk) dan kontrol positif (pupuk kompos komersial). Pelaksanaan percobaan dilakukan di ruang kondisi suhu $23^{\circ} \mathrm{C}$, foto periode $12 \mathrm{jam}$ terang 12 jam gelap, kelembapan $70 \pm 5 \%$ di siang hari dan $90 \pm 5 \%$ di malam hari. Intensitas cahaya selama percobaan dipantau. Sebelum dilakukan percobaan, masing-masing pelet pupuk dihaluskan, dihomogenkan, kemudian dianalisis kadar airnya. Peralatan dan media pasir serta bahan-bahan yang akan digunakan disterilkan, tempat untuk perkecambahan biji (seeding tray) dibersihkan dengan alkohol 70\%.

Percobaan dilakukan pada $50 \mathrm{~g}$ media pasir steril yang ditempatkan dalam seeding tray dan ditambah pelet pupuk organik sesuai variasi dosis yang telah ditetapkan. Pada setiap media pasir dari masing-masing perlakuan disemaikan satu biji tanaman tomat, kemudian disiram dengan air RO. Setiap seeding tray diberi alas wadah aluminium yang diisi air RO untuk mempertahankan kelembapan. Pengamatan dilakukan terhadap perkecambahan biji dan kondisi tanaman setiap hari. Panen kecambah dilakukan setelah 21 hari pengamatan terhitung sejak $50 \%$ kontrol positif berkecambah. Pengukuran tinggi tunas dilakukan pada akhir pengamatan.

\section{HASIL DAN PEMBAHASAN}

\section{Karakteristik Residu Proses Digestasi Anaerobik}

Residu proses digestasi anaerobik berupa lumpur, yang selanjutnya disebut residu lumpur, merupakan lumpur yang telah terdegradasi secara anaerobik, namun tidak terkonversi menjadi gas akan mengendap dalam tangki pengendap. Komposisi residu lumpur tersebut banyak mengandung elemen-elemen unsur hara makro dan mikro yang dibutuhkan tanaman. Hasil analisis karakteristik residu lumpur tersebut dapat dilihat pada Tabel 1. Standar mutu yang digunakan sebagai acuan persyaratan minimal dari produk pupuk hasil penelitian ini adalah PERMENTAN No. 70/2011 dan SNI 7847:2012. Residu lumpur yang digunakan pada penelitian ini memiliki rasio C/N 15 yang artinya memenuhi persyaratan baku mutu tersebut. Selain rasio $\mathrm{C} / \mathrm{N}$, data karakteristik residu lumpur lainnya menunjukkan bahwa parameter uji yang meliputi unsur hara makro dan mikro telah memenuhi persyaratan minimal pupuk organik, kecuali unsur hara mikro Zn menunjukkan nilai lebih tinggi dari SNI. Namun, unsur hara mikro Zn pada residu lumpur digestasi anaerobik industri kertas menurut hasil penelitian Purwati dkk. (2011) dan Rina dkk. (2012) menunjukkan nilai yang jauh lebih rendah yaitu masing-masing $15 \mathrm{mg} / \mathrm{kg}$ dan $77 \mathrm{mg} / \mathrm{kg}$. Adanya perbedaan tersebut dapat disebabkan oleh fluktuasinya proses digestasi anaerobik atau karakteristik lumpur biologi sebagai umpan proses digestasi anaerobik. Kadar air residu lumpur $8,79 \%$ menunjukkan nilai yang terlalu rendah apabila dibandingkan dengan persyaratan pupuk organik bentuk curah dan pembenah tanah menurut PERMENTAN No. 70 tahun 2011 dan SNI 7847:2012, hal tersebut terjadi disebabkan karena proses pengeringan residu lumpur yang terlalu lama. Kadar air residu lumpur digestasi anaerobik sebelum dikeringkan masih sangat tinggi, yaitu 98,3-98,8\%. Apabila residu lumpur tersebut dibuat sebagai pelet pupuk organik, 
Tabel 1. Karakteristik Residu Proses Digestasi Anaerobik

\begin{tabular}{|c|c|c|c|c|c|c|c|}
\hline \multirow{3}{*}{ No. } & \multirow{3}{*}{ Parameter } & \multirow{3}{*}{ Satuan } & \multirow{3}{*}{$\begin{array}{l}\text { Hasil Uji } \\
\text { Residu } \\
\text { Lumpur }\end{array}$} & \multicolumn{4}{|c|}{ Standar Mutu } \\
\hline & & & & \multirow{2}{*}{$\begin{array}{c}\text { SNI } \\
7847: 2012\end{array}$} & \multicolumn{3}{|c|}{ PERMENTAN 70/2011 } \\
\hline & & & & & A & $\mathrm{B}$ & $\mathrm{C}$ \\
\hline 1 & $\mathrm{C}$ - organik & $\%$ & 20,63 & $\geq 10$ & $\min .15$ & $\min .15$ & $\min .15$ \\
\hline 2 & $\mathrm{C} / \mathrm{N}$ rasio & & 15 & 10 s.d 25 & 15 s.d 25 & 15 s.d 25 & 15 s.d 25 \\
\hline 3 & Bahan ikutan ${ }^{1)}$ & $\%$ & 0 & - & maks. 2 & maks. 2 & maks. 2 \\
\hline 4 & Kadar Air & $\%$ & 8,79 & $\leq 50$ & 15 s.d 25 & 8 s.d 20 & 15 s.d 25 \\
\hline 5 & $\begin{array}{l}\text { Logam berat } \\
\text { - } \mathrm{As} \\
\text { - } \mathrm{Hg} \\
\text { - } \mathrm{Pb} \\
\text { - } \mathrm{Cd} \\
\text { - } \mathrm{Cr} \\
\text { - } \mathrm{Co} \\
\text { - } \mathrm{Ni} \\
\text { - } \mathrm{Se} \\
\text { - } \mathrm{Sn}\end{array}$ & $\begin{array}{l}\text { ppm } \\
\text { ppm } \\
\text { ppm } \\
\text { ppm } \\
\text { ppm } \\
\text { ppm } \\
\text { ppm } \\
\text { ppm } \\
\text { ppm }\end{array}$ & $\begin{array}{c}6 \\
0,8^{2)} \\
5 \\
\text { td } \\
3 \\
7 \\
12 \\
\text { td } \\
-\end{array}$ & $\begin{array}{l}\text { maks. } 10 \\
\text { maks. } 0,8 \\
\text { maks. } 50 \\
\text { maks. } \quad 3 \\
\text { maks. } 210 \\
\text { maks. } 20 \\
\text { maks. } 50 \\
\text { maks. } 1,0 \\
\text { maks. } 20\end{array}$ & $\begin{array}{lr}\text { maks. } & 10 \\
\text { maks. } & 1 \\
\text { maks. } & 50 \\
\text { maks. } & 2 \\
\text { maks. } & 210 \\
\text { maks. } & 700 \\
\text { maks. } & 62 \\
\text { maks. } & 2 \\
- & \end{array}$ & $\begin{array}{l}\text { maks. } 10 \\
\text { maks. } 1 \\
\text { maks. } 50 \\
\text { maks. } 2 \\
- \\
- \\
- \\
- \\
-\end{array}$ & $\begin{array}{ll}\text { maks. } & 10 \\
\text { maks. } & 1 \\
\text { maks. } & 50 \\
\text { maks. } & 2 \\
- & \\
- & \\
- & \\
- & \\
- & \end{array}$ \\
\hline 6 & $\mathrm{pH}$ & - & 6,8 & 6 s.d 8 & 4 s.d 9 & 4 s.d 9 & 4 s.d 9 \\
\hline 7 & $\begin{array}{l}\text { Hara makro } \\
\left(\mathrm{N}+\mathrm{P}_{2} \mathrm{O}_{5}+\mathrm{K}_{2} \mathrm{O}\right)\end{array}$ & $\%$ & 9,55 & - & $\min .4$ & $\min .4$ & $\min .4$ \\
\hline 8 & $\begin{array}{l}\text { Mikroba kontamin.an: } \\
\text { - E.coli } \\
\text { - Salmonella sp }\end{array}$ & $\begin{array}{l}\mathrm{MPN} / \mathrm{g} \\
\mathrm{MPN} / \mathrm{g}\end{array}$ & $\begin{array}{l}<30 \\
<30\end{array}$ & - & $\begin{array}{l}\text { maks. } 10^{2} \\
\text { maks. } 10^{2}\end{array}$ & $\begin{array}{l}\text { maks. } 10^{2} \\
\text { maks. } 10^{2}\end{array}$ & $\begin{array}{l}\text { maks. } 10^{2} \\
\text { maks. } 10^{2}\end{array}$ \\
\hline 9 & $\begin{array}{l}\text { Ukuran butiran } \\
2-5 \mathrm{~mm}\end{array}$ & $\%$ & - & - & - & $\min .80$ & - \\
\hline 10 & Hara mikro : & & & & & & \\
\hline & $\begin{array}{l}\text { - } \mathrm{Fe} \text { total } \\
\text { - } \mathrm{Fe} \text { tersedia } \\
\text { - } \mathrm{Mn} \\
\text { - } \mathrm{Zn} \\
\text { - } \mathrm{Cu} \\
\text { - } \mathrm{Mo}\end{array}$ & $\begin{array}{l}\text { ppm } \\
\text { ppm } \\
\text { ppm } \\
\text { ppm } \\
\text { ppm } \\
\text { ppm }\end{array}$ & $\begin{array}{c}3435 \\
- \\
514 \\
2791 \\
43 \\
\mathrm{Td}\end{array}$ & $\begin{array}{l}- \\
- \\
- \\
\text { maks. } 500 \\
\text { maks. } 100 \\
\text { maks. } 10\end{array}$ & $\begin{array}{lr}\text { maks. } & 9000 \\
\text { maks. } & 500 \\
\text { maks. } & 5000 \\
\text { maks. } & 5000 \\
\text { maks. } & 5000 \\
\text { maks. } \quad 20\end{array}$ & $\begin{array}{l}\text { maks. } 9000 \\
\text { maks. } 500 \\
\text { maks. } 5000 \\
\text { maks. } 5000 \\
- \\
-\end{array}$ & $\begin{array}{l}\text { maks. } 9000 \\
\text { maks. } 500 \\
\text { maks. } 5000 \\
\text { maks. } 5000 \\
- \\
-\end{array}$ \\
\hline 11 & $\begin{array}{l}\text { Unsur lain : } \\
\text { - } \mathrm{La} \\
\text { - } \mathrm{Ce}\end{array}$ & $\begin{array}{l}\mathrm{ppm} \\
\mathrm{ppm}\end{array}$ & $\begin{array}{l}0 \\
0\end{array}$ & - & $\begin{array}{l}0 \\
0\end{array}$ & $\begin{array}{l}0 \\
0\end{array}$ & $\begin{array}{l}0 \\
0\end{array}$ \\
\hline 12 & $\begin{array}{l}\text { Total } \mathrm{Na} \\
\text { Total } \mathrm{Cl}\end{array}$ & $\begin{array}{l}\text { ppm } \\
\text { ppm }\end{array}$ & $\begin{array}{c}1300 \\
-\end{array}$ & - & $\begin{array}{l}\text { maks. } 2000 \\
\text { maks. } 5000\end{array}$ & - & - \\
\hline $\begin{array}{l}\text { Ketera } \\
\text { 1). Bah } \\
\text { 2). Das } \\
\text { A. Tab } \\
\text { B. Tab } \\
\text { C Tah }\end{array}$ & $\begin{array}{l}\text { ngan : } \\
\text { an plastik, kaca, kerikil } \\
\text { ar kadar air 25\% } \\
\text { l Persyaratan Teknis Min.l } \\
\text { l Persyaratan Teknis Min.l } \\
\text { l Persyaratan Teknis Min. }\end{array}$ & upuk & Padat & l/Pelet $\mathrm{Mu}$ & Air Limbah & & \\
\hline
\end{tabular}

pengeringan sampai kadar air 8,79\% tersebut sudah memenuhi syarat PERMENTAN No. 70 tahun 2011. Kandungan logam berat dalam residu lumpur menunjukkan nilai di bawah persyaratan pupuk organik dan pembenah tanah yang berasal darilimbah industrimenurut PERMENTANNo. 70 tahun 2011 maupun SNI 7847:2012. Hasil tersebut sesuai dengan hasil penelitian Rina dkk. (2012) yang menyatakan bahwa residu lumpur proses digestasi anaerobik memiliki potensi untuk dimanfaatkan sebagai pupuk.

Agar pemanfaatan residu lumpur ini dapat diterapkan, maka perlu diperhatikan penyimpanan dan transportasi pupuk ke lahan aplikasinya. Untuk memudahkan penyimpanan dan transportasinya, residu lumpur tersebut yang 
dapat dikatakan sebagai pupuk organik curah dibuat dalam bentuk pelet dengan menambah bahan perekat.

\section{Hasil Pembuatan Pelet Pupuk Organik}

Pelet pupuk organik dibuat berukuran $3 \mathrm{~mm}$ $-5 \mathrm{~mm}$ dengan berbagai bahan perekat dan dosis perekat. Perubahan fisik pupuk organik dari curah menjadi pelet diperlukan kekuatan fisik yang tidak mudah hancur, namun unsur haranya masih tetap mudah diabsorbsi oleh tanaman. Perekat yang digunakan adalah tepung kanji, tepung sagu, dan molase dengan pertimbangan bahwa tepung kanji dan tepung sagu merupakan karbohidrat yang terdiri dari banyak glukosa yang bergabung karena adanya ikatan glikosida yang disebut sebagai pati (starch). Pati bila terlarut dalam air dapat berfungsi sebagai perekat (Kuokkanen, 2013). Sementara, molase adalah limbah proses pembuatan gula dari tebu yang dapat juga digunakan sebagai perekat (Olbrich, 2006). Hasil uji komposisi perekat dapat dilihat pada Tabel 2.

Tabel 2. Karakteristik Bahan Perekat

\begin{tabular}{lcccc}
\hline $\begin{array}{c}\text { Jenis } \\
\text { Perekat }\end{array}$ & $\begin{array}{c}\text { Kadar } \\
\text { Air (\%) }\end{array}$ & $\begin{array}{c}\text { Kadar C } \\
\text { Organik } \\
(\%)\end{array}$ & $\begin{array}{c}\text { Total } \\
\text { Nitrogen } \\
(\%)\end{array}$ & C/N \\
\hline Kanji & $13,36 \%$ & $50,13 \%$ & $0,24 \%$ & 209 \\
Sagu & $10,35 \%$ & $51,88 \%$ & $0,19 \%$ & 273 \\
Molase & $37,27 \%$ & $37,24 \%$ & - & $18 *$ \\
\hline *Rahn dkk, 2003 & & &
\end{tabular}

Secara umum, karakteristik tepung kanji dan tepung sagu relatif memiliki rasio $\mathrm{C} / \mathrm{N}$ sangat tinggi. Tingginya rasio $\mathrm{C} / \mathrm{N}$ pada bahan tersebut karena kandungan utama tepung kanji dan tepung sagu adalah pati. Kuokkanen (2013) menjelaskan bahwa pati umumnya terdiri dari $20-25 \%$ amilosa dan $75-80 \%$ amilopektin tergantung dari jenis tanamannya. Mengacu pada Rahn dkk. (2003), molase memiliki rasio C/N $=18$. Nilai tersebut lebih rendah dibandingkan tepung kanji dan tepung sagu. Data pengukuran $\mathrm{pH}$, baik tanpa perekat maupun dengan perekat kanji, sagu dan molase berada pada kisaran netral, yaitu rata-rata $6,88(6,71-7,15)$ dan memenuhi persyaratan pelet pupuk organik dalam PERMENTAN No. 70 Tahun 2011 (4-9) dan SNI 7847:2012 (6-8).

\section{Hasil Uji Fisik Produk Pelet dengan Perekat}

Perubahan sifat fisik residu lumpur sebagai pupuk organik curah menjadi pupuk organik dalam bentuk pelet dapat diketahui dari hasil uji sifat fisik pelet meliputi yield, densitas, water holding capacity dan durabilitas. Gambar 1 menunjukkan hubungan antara dosis perekat terhadap sifat fisik pelet yield, densitas, dan water holding capacity. Dari ketiga parameter fisik tersebut, hanya parameter water holding capacity yang menunjukkan adanya penurunan dibandingkan tanpa perekat.

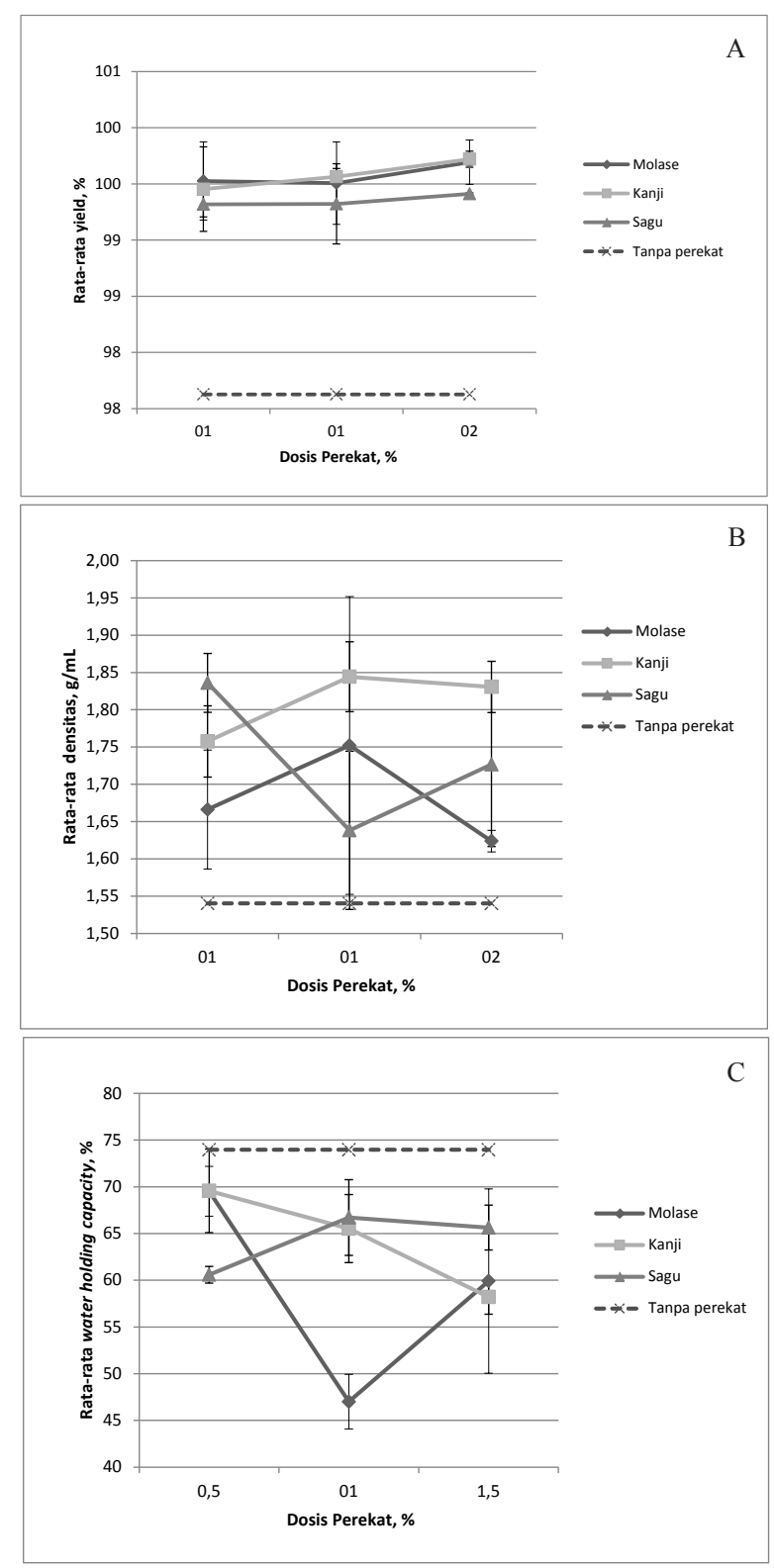

Gambar 1. Hubungan antara Jenis dan Dosis Perekat terhadap Sifat-sifat Fisik Pelet Pupuk Organik. A: Yield; B: Densitas; C : Water Holding Capacity 
Berdasarkan data pada Gambar 1C, water holding capacity pelet dengan ketiga jenis perekat lebih kecil dibandingkan dengan pelet tanpa perekat. Hal tersebut tampak pada penambahan dosis terkecil $0,5 \%$ perekat molase dan kanji memberikan water holding capacity lebih tinggi dibandingkan dosis $1 \%$ dan 1,5\%. Dengan kata lain, ada kecenderungan bahwa penambahan perekat justru menurunkan water holding capacity. Water holding capacity dipengaruhi oleh susunan partikel yang terkandung dalam bahan organik. Penambahan pupuk organik ke tanah akan meningkatkan water holding capacity, hal tersebut terjadi karena pupuk organik memiliki kemampuan untuk meningkatkan jumlah mikropori dan makropori tanah (Bot dan Benitez, 2005). Makropori memiliki diameter pori $\geq 0.1 \mathrm{~mm}$, sementara mikropori $<0,1 \mathrm{~mm}$ (Shober, 2008).

Secara keseluruhan, berdasarkan ketiga sifat fisik pelet pada Gambar 1., perekat kanji dan perekat sagu cenderung lebih baik dari pada perekat molase. Jika sifat fisik pelet antara perekat kanji dan perekat sagu dibandingkan, maka tampak bahwa perekat kanji cenderung lebih baik. Dosis terbaik perekat kanji pada pembuatan pelet pupuk organik dari residu proses digestasi anaerobik adalah 1,0\%. Penetapan dosis terbaik tersebut dilakukan berdasarkan sifat fisik yield dan densitas tertinggi yang diperoleh dari dosis perekat kanji 1,0 - 1,5\%, yaitu masingmasing $99,56-99,72 \%$ dan $1,83-1,84 \mathrm{mg} / \mathrm{mL}$, sedangkan sifat fisik water holding capacity tertinggi diperoleh pada dosis $0,5-1,0 \%$ dengan nilai $65,5-69,6 \%$.

Alemi dkk. (2010) menjelaskan bahwa durabilitas merupakan sifat fisik yang menunjukkan ketahanan pelet terhadap kerusakan dalam pengangkutan dan transportasinya. Hasil uji durabilitas pelet dapat dilihat pada Gambar 2. Secara keseluruhan, penambahan perekat dapat meningkatkan durabilitas dibandingkan tanpa perekat, kecuali perekat molase pada dosis rendah $(0,5 \%)$. Hal tersebut sejalan dengan hasil penelitian Gunawan dkk. (2015) yang menjelaskan bahwa perekat kanji (tapioka) lebih baik dari molase. Adanya perbedaan tersebut disebabkan oleh komposisi kimia dari masingmasing perekat berbeda. Komposisi kimia tepung sagu dan tepung kanji terdiri dari karbohidrat kompleks (amilopektin) yang bersifat lengket, sedangkan molase tidak mengandung amilopektin. Komponen utama molase adalah sukrosa yang merupakan gula sederhana. Amilopektin yang bersifat lengket dapat meningkatkan ikatan antar material-material dalam pelet pupuk organik sehingga dapat meningkatkan ketahanan terhadap tekanan dan gesekan yang diterima pelet saat pengangkutan dan transportasi. Hal tersebut sesuai dengan Kuokkanen (2013) yang menjelaskan bahwa tepung sagu dan tepung kanji mengandung polisakarida kompleks berupa amilum (starch) yang umum digunakan sebagai perekat (Kuokkanen, 2013).

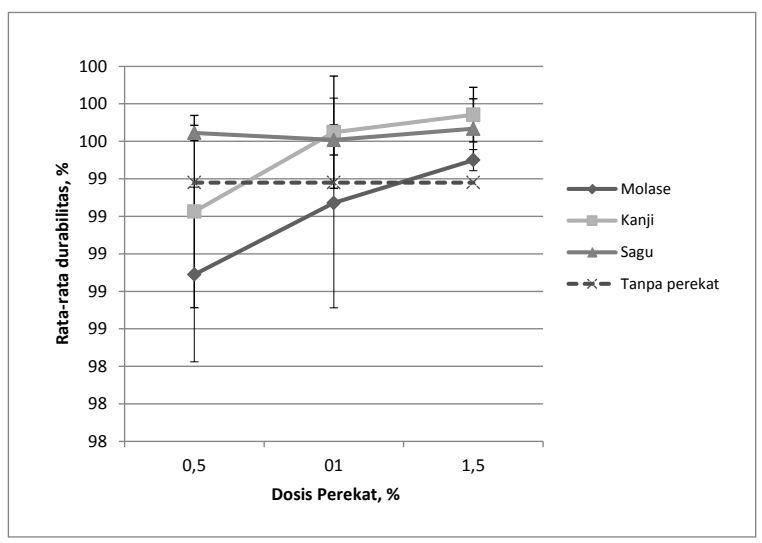

Gambar 2. Durabilitas Pelet Pupuk Organik

Menurut standar CSN-EN-14961-6, pelet non wood harus mempunyai nilai durabilitas minimal 96\%. Pada penelitian ini, sifat fisik durabilitas yang dihasilkan pelet dengan tiga variasi perekat menunjukkan nilai di atas persyaratan minimal untuk semua perlakuan dosis $0,5 \%-1,5 \%$. Nilai durabilitas pelet dengan masing-masing jenis perekat tersebut, yaitu $98,89 \%-99,50 \%$ untuk pelet dengan perekat molase; 99,23\%-99,74\% untuk pelet dengan perekat tepung kanji; 99,61\%$99,67 \%$ untuk pelet dengan perekat tepung sagu (Gambar 2). Walaupun penggunaan ketiga jenis perekat tersebut menunjukkan nilai durabilitas di atas persyaratan, namun pelet dengan perekat kanji dan sagu menunjukkan durabilitas yang cenderung lebih tinggi daripada dengan perekat molase (Gambar 2).

Berdasarkan hasil uji statistik, diketahui bahwa pelet pupuk dengan perekat molase $0,5 \%$ memiliki nilai durabilitas lebih rendah dan berbeda nyata dengan pupuk tanpa perekat. Sementara, nilai durabilitas yang lebih tinggi dan berbeda nyata dengan pupuk tanpa perekat diperoleh pada perlakuan pelet pupuk dengan perekat tepung sagu pada semua dosis dan pupuk dengan perekat tepung kanji pada dosis $1,0 \%$ dan $1,5 \%$. 
Dari hasil uji fisik dapat disimpulkan bahwa diantara 3 perekat yang digunakan, penambahan tepung kanji memberikan peningkatan sifat fisik pelet yang paling baik dibandingkan tepung sagu dan molase.

\section{Pengaruh Pelet Pupuk terhadap Perkecambahan Biji Tomat}

Tabel 3 menunjukkan persentase perkecambahan dan durabilitas tomat pada media tanam yang telah diberi perlakuan pelet pupuk dengan variasi perekat. Menurut OECD (www.oecd.org), hasil percobaan ini dinyatakan valid jika kemampuan biji berkecambah pada media kontrol positif mencapai $80 \%$ dengan rata-rata yang bertahan tumbuh minimal $90 \%$.
Data perkecambahan pada Tabel 3 menunjukkan bahwa persentase pertumbuhan kecambah dari kontrol positif melebihi $80 \%$ dengan durabilitas mencapai $100 \%$ sehingga dapat dikatakan hasil percobaan ini adalah valid. Perkecambahan biji tomat pada media yang ditambah pelet pupuk dengan variasi perekat secara keseluruhan menunjukkan pertumbuhan kecambah 100\%, kecuali pada media yang diberi pelet pupuk berperekat tepung kanji $0,375 \mathrm{~g} / \mathrm{g}$ media dan $0,5 \mathrm{~g} / 50 \mathrm{~g}$ media dan berperekat molase $0,250 \mathrm{~g} / \mathrm{g}$ media dan $0,375 \mathrm{~g} / 50 \mathrm{~g}$ media.

Data pengamatan tinggi tunas tanaman tomat dapat dilihat pada Tabel 4. Hasil uji statistik terhadap pertumbuhan tinggi tunas menunjukkan bahwa perlakuan pelet pupuk dengan variasi perekat tidak berbeda nyata dibandingkan

Tabel 3. Persentase Perkecambahan dan Durabilitas dari Biji Tomat

\begin{tabular}{|c|c|c|c|}
\hline \multirow{2}{*}{ Jenis Perlakuan } & \multirow{2}{*}{$\begin{array}{c}\text { Dosis } \\
\text { (g/50 g media) }\end{array}$} & \multicolumn{2}{|c|}{ Persentase } \\
\hline & & Perkecambahan & Durabilitas \\
\hline Kontrol negatif & 0 & $100 \%$ & $100 \%$ \\
\hline \multirow{4}{*}{ Kontrol positif } & 0,125 & $83 \%$ & $100 \%$ \\
\hline & 0,25 & $100 \%$ & $100 \%$ \\
\hline & 0,375 & $100 \%$ & $100 \%$ \\
\hline & 0,5 & $100 \%$ & $100 \%$ \\
\hline \multirow{4}{*}{ Pelet pupuk tanpa perekat } & 0,125 & $100 \%$ & $100 \%$ \\
\hline & 0,25 & $100 \%$ & $100 \%$ \\
\hline & 0,375 & $100 \%$ & $100 \%$ \\
\hline & 0,5 & $100 \%$ & $100 \%$ \\
\hline \multirow{4}{*}{ Pelet pupuk dengan perekat tepung sagu } & 0,125 & $100 \%$ & $100 \%$ \\
\hline & 0,25 & $100 \%$ & $100 \%$ \\
\hline & 0,375 & $100 \%$ & $100 \%$ \\
\hline & 0,5 & $100 \%$ & $100 \%$ \\
\hline \multirow{4}{*}{ Pelet pupuk dengan perekat tepung kanji } & 0,125 & $100 \%$ & $100 \%$ \\
\hline & 0,25 & $100 \%$ & $100 \%$ \\
\hline & 0,375 & $83 \%$ & $100 \%$ \\
\hline & 0,5 & $83 \%$ & $100 \%$ \\
\hline \multirow{4}{*}{ Pelet pupuk dengan perekat molase } & 0,125 & $100 \%$ & $100 \%$ \\
\hline & 0,25 & $83 \%$ & $100 \%$ \\
\hline & 0,375 & $67 \%$ & $100 \%$ \\
\hline & 0,5 & $100 \%$ & $100 \%$ \\
\hline
\end{tabular}


Tabel 4. Data Tinggi Tunas Tomat

\begin{tabular}{lccccccccc}
\hline \multirow{2}{*}{ Perlakuan/ Dosis } & \multicolumn{7}{c}{ Dosis Pelet Pupuk Organik (g/50 g media) } \\
\cline { 2 - 9 } & \multicolumn{2}{c}{0,125} & \multicolumn{2}{c}{0,250} & & 0,375 & \multicolumn{2}{c}{0,50} \\
\hline Pupuk tanpa perekat & 4,62 & abc & 5,02 & bc & 3,57 & abc & 3,70 & abc \\
Pupuk dengan perekat tepung sagu & 3,58 & abc & 3,52 & abc & 4,90 & bc & 5,53 & $\mathrm{c}$ \\
Pupuk dengan perekat tepung kanji & 5,53 & $\mathrm{c}$ & 5,03 & $\mathrm{bc}$ & 3,10 & $\mathrm{abc}$ & 2,95 & $\mathrm{abc}$ \\
Pupuk dengan perekat molase & 5,18 & $\mathrm{c}$ & 3,52 & $\mathrm{abc}$ & 2,48 & $\mathrm{ab}$ & 4,05 & $\mathrm{abc}$ \\
Kontrol positif & 3,80 & abc & 5 & $\mathrm{bc}$ & 4,95 & $\mathrm{bc}$ & 2,22 & $\mathrm{a}$ \\
Kontrol negatif & 4,38 & abc & 4,38 & abc & 4,38 & abc & 4,38 & abc \\
\hline
\end{tabular}

Keterangan : Huruf yang sama pada kolom yang sama menunjukkan tidak berbeda nyata

dengan perlakuan pelet pupuk tanpa perekat, kontrol negatif, dan kontrol positif, kecuali perlakuan pelet pupuk dengan perekat tepung sagu pada dosis $0,5 \mathrm{~g} / 50 \mathrm{~g}$ media. Perlakuan tersebut menghasilkan tunas yang lebih tinggi dan berbeda nyata dibandingkan kontrol positif sehingga dapat dikatakan bahwa pupuk dengan perekat tepung sagu pada dosis $0,5 \mathrm{~g} / 50 \mathrm{~g}$ media merupakan jenis dan dosis pupuk yang optimal.

\section{KESIMPULAN}

Komposisi residu proses digestasi anaerobik mengandung unsur hara makro dan mikro yang memenuhi syarat sebagai pupuk organik baik sebagai pupuk curah maupun pelet pupuk menurut PERMENTAN No. 70 tahun 2011 kecuali kadar air dan pembenah tanah menurut SNI 7847:2012 kecuali hara mikro Zn. Perubahan bentuk fisik pupuk organik dari curah menjadi bentuk pelet berukuran $3-5 \mathrm{~mm}$ dapat dilakukan dengan penambahan bahan perekat. Penambahan perekat tepung kanji $1 \%$ memberikan peningkatan terhadap sifat-sifat fisik meliputi yield, densitas, dan durabilitas yang lebih baik dibandingkan dengan molase dan tepung sagu. Pelet dengan perekat tepung kanji $1 \%$ memiliki sifat fisik, antara lain yield $99,56 \%$, densitas $1,84 \mathrm{~g} / \mathrm{ml}$, water holding capacity $65,53 \%$ dan durabilitas $99,65-99,84 \%$. Penggunaan pelet pupuk organik berperekat tepung sagu $0,5 \mathrm{~g} / 50 \mathrm{~g}$ media merupakan yang terbaik untuk perkecambahan dan pertumbuhan biji tanaman tomat.

\section{UCAPAN TERIMA KASIH}

Penulis mengucapkan terima kasih yang sebesar besarnya kepada Ibu Sri Purwati atas masukannya selama pelaksanaan penelitian.

\section{DAFTAR PUSTAKA}

Allaire,S.E, Parent, L.E. 2003. Physical Properties of Granular Organic-Based Fertilisers, Part 1 : Static Properties. Biosystem Engineering (2004) 87 (1), 79-87

Alemi, H., Kianmehr, M.H., Borghaee, A.M. 2010. Effect of Pellet Processing of Fertilizer on Slow-Release Nitrogen in Soil. Asian Journal of Plant Sciences, 9,74-80.

ASAE S269.4 DEC96. 1996. Cubes, Pellets, and Crumbles-Definitions and Methods for Determining Density, Durability, and Moisture Content.

Bot, A., Benitez, J., 2005. The Importance of Soil Organic Matter. Food and Agricultural Organization of the United Nations. Rome

CSN EN 14961-6. 2012. Solid biofuels-Fuel Specification Industrial Use. Praha: Urad Pro Technickou Normalizaci, Metrologii a Statni Zkusebnictvi

Gunawan, M.S., Nawansih,O., Nurainy, F. 2015. The application of The Use an Adhesive Material Towards Physical and Chemical Characteristic of Organic Fertilizers Granule That Feedstock of Compost The Rind of Cocoa. Seminar Nasional Sains \& Technology VI. Lembaga Penelitian dan Pengabdian Universitas Lampung.

Hara, M., 2001. Fertilizer Pelets Made from Composted Livestock Manure. Agriculture Research Division Mie Prefectural Science and Technology Promotion Center

Isroi. 2009. Pupuk Organik Granul: Sebuah Petunjuk Praktis. C.V. Andi Offset Yogyakarta

Kuokkanen, M. 2013. Development of an Eco-and Material-Efficient Pellet Production Chain-a Chemical Studiy.Dissertation. University of Oulu, Oulu.

Nikiema, J., Cofie, O., Impraim, R., Adamtey, N., 2013. Processing of Fecal Sludge to Fertilizer Pellets Using a Low-Cost Technology in Ghana. Environment and Pollution, Vol. 2, No. 4 
Olbrich, Hubert. 2006. The Molasses. Publish by Biotechnologie -Kempe GmbH (2006). http:// www.biotechnologie-kempe.de/Molasses OLBRICH.pdf

Purwati, S., Rina, S.S., Idiyanti, T. 2011. Aplikasi Protease dan Pengaruh Suhu pada Asidifikasi Asidifikasi Digestasi Anaerobik Dua Tahap Lumpur IPAL Biologi Industri Kertas. Jurnal Selulosa. Vol. 1, No. 1, Juni 2011.

Rahn,C.R., Bending, G.D.,Turner, M.K., Lillywhite, R.D. 2003. Management of $\mathrm{N}$ Mineralization from Crop Residues of High $\mathrm{N}$ Content Using Amendment Materials of Varying Quality. Soil Use and Management (2003) 19, 193-200

Rina, S.S., Purwati, S., Setiawan ,Y. Wardhana, K.A., 2012, Pengembangan Proses Digestasi Anaerobik Lumpur Biologi IPAL Industri Kertas untuk Meningkatkan Nilai Ekonomi Pemanfaatan Limbah, Jurnal Riset Industri Vol. VI No. 2, 193-202

Shober, A.L. 2008. Soils and Fertilizers for Master Gardener : Soil Physical Properties. http:// edis.ifas.ufl.edu/pdffiles/MG/MG45100.pdf
Suriadikarta, D. A., Setyorini, D. 2006. Pupuk Organik dan Pupuk Hayati. Balai Besar Litbang Sumberdaya Lahan Pertanian. Hal .238 .

Utari, N.W.A, Tamrin, Triyono, S. 2015. Kajian Karakteristik Fisik Pupuk Organik Granul Dengan Dua Jenis Bahan Perekat. Jurnal Teknik Pertanian Lampung, Vol. 3, No.3, 267274

Viji,R., Rajesh, P.P.2011. Assesment of Water Holding Capacity of Major Soil Series of Lalgudi, Trichy, India. J.Environ. Res. Develop. Vol. 7 No.1A, July-September 2012. Wahyono, S., Sahwan, F.L, Suryanto, F. 2011. Membuat Pupuk Organik Granul Dari Aneka Limbah. PT. Argomedia Pustaka: Jakarta.

http://www.oecd.org/chemicalsafety/ testing/33653757.pdf. Guidelines for the Testing of Chemicals. Terrestrial Plant Test: 208 : Seedling Emergence and Seedling Growth Test (diakses tanggal 19 Juni2014) 